\section{References}

Abas, M., Vanderpyl, J., Prou, T. L., et al (2003) Psychiatric hospitalization: reasons for admission and alternatives to admission in South Auckland, New Zealand. Australian and New Zealand Journal of Psychiatry, 37, 620-625.

Clifford, P. I. (1999) The FACE recording and measurement system: a scientific approach to person-based information. Bulletin of the Menninger Clinic, 63, 305-331.

Cotton, M. A., Johnson, S., Bindman, J., et al (2007) An investigation of factors associated with psychiatric hospital admission despite the presence of crisis resolution teams. BMC Psychiatry, 7, 52.

Government of Ireland (2006a) A Vision for Change. Report of the Expert Group on Mental Health Policy. Stationery Office.

Government of Ireland (2006b) Census Report. Central Statistics Office.

Hatfield, B., Spurrell, M. \& Perry, A. (2000) Emergency referrals to an acute psychiatric service: demographic, social and clinical characteristics and comparisons with those receiving continuing services. Journal of Mental Health, 9, 305-317.

Johnson, S., Nolan, F., Pilling, S., et al (2005) Randomised controlled trial of acute mental health care by a crisis resolution team: the North Islington Crisis Study. BMJ, 331, 599-602.

Minghella, E., Ford, R. \& Freeman, T. (1998) Open All Hours: 24-Hour Response for People with Mental Health Emergencies. Sainsbury Centre for Mental Health.

Neu, D., Minner, P., Le Bon, O., et al (2009) Significance of fatigue and insomnia complaints in the psychiatric emergency room. European Neuropsychopharmacology, 19, S243-S244.

SPSS Inc. (2009) PASW Statistics (18.0). SPSS Inc.

Spurrell, M., Hatfield, B. \& Perry, A. (2003) Characteristics of patients presenting for emergency psychiatric assessment at an English hospital. Psychiatric Services, 54, 240-245.

\title{
Challenges for psychiatry in the 21st century
}

\section{Dinesh Bhugra PhD FRCPsych}

Professor of Mental Health and Cultural Diversity, Health Service \& Population Research Department, Institute of Psychiatry, King's College London, UK, email Dinesh.bhugra@kcl.ac.uk

\section{$\mathrm{P}$} sychiatrists manage ambiguity in diagnosis as well as management of patients with psychiatric disorders and contain anxiety experienced by patients and their families as well as that of the teams. The changes in societies and cultures in the past few decades have produced changes in their expectations of their doctors, including psychiatrists. In some high-income countries, patients are better informed about their conditions and treatments than they were before. This availability of knowledge has led to a levelling in the relationship between patient and doctor.

In this paper I highlight some of the challenges psychiatry as a profession and psychiatrists as clinicians face in the early part of the 21 st century. These challenges can be divided into broad categories of social, biological and psychological factors. Social factors include globalisation and urbanisation as a result of increasing industrialisation in several countries across the globe. Biological factors include pharmacogenomics as a result of gene mapping and newer pharmacological agents. Psychological factors include computer-based therapies and stigma against patients and the profession itself.

\section{Globalisation, urbanisation and industrialisation}

Globalisation describes better communications and ease of movement of people, materials and products. The process of globalisation influences not only market forces but the political and social functioning of societies as well (see Gupta \& Bhugra, 2009; Bhugra \& Gupta, 2011). Countries can be broadly divided into: those which provide raw materials for production; those which manufacture goods; and those which are largely consumers. The movement of professionals has similar pathways. Countries may produce healthcare professionals at a lower cost but then lose them to countries which pay higher salaries, leading to serious brain drain.

Within low- and middle-income countries, increased industrialisation will lead to increased urbanisation as it did in high-income countries centuries ago. This process may cause fragmentation of families, a reduction in social support and an increase in demand for healthcare services. Furthermore, after internal migration, individuals may find that their aspirations in a number of areas are not met, which lowers self-esteem.

These factors in turn will cause changes in cultural beliefs, attitudes and values such as deculturation, affecting the individual's functioning. As a majority of the world's population is likely to reside in urban areas in the next three decades, clinicians need to be aware of the potential needs that these populations may have.

\section{Pharmacogenomics}

With new means of identifying pathology such as gene mapping, it is likely that, in due course, there will be specific medications tailored to individuals. Mrazek (2010, p. 3) defines psychiatric pharmacogenomics as the study of how gene variations influence the response of a patient to psychotropic medication. An understanding of the structural gene variants may allow drug side-effects to be minimised and genetic testing may allow the creation of bespoke 
medications for individuals. However, there are a number of key ethical and technical issues: appropriate consent, voluntary or compulsory testing, confidentiality of medical information and reliability of these tests (Mrazek, 2010, p. 231).

\section{Talking therapies without therapists}

With many behavioural and cognitive-behavioural therapies available on computer, with clear algorithms and steps for home work, will psychotherapists and therapists be required? Patients prefer their psychiatrists to have good communication skills (Bhugra \& Gupta, 2010). Medicine and doctoring are about caring and curing and the human and humane touch with people who are suffering. Psychotherapy is at the core of what we do - whether we are persuading patients to take their medication as prescribed, exploring their inner world and turmoil or helping modify their cognitive schema, psychiatry and psychiatrists have a major role to play.

\section{Stigma}

Stigma, discrimination and prejudice against mental illness and those with mental disorder remain a major challenge to psychiatry, although the fact that more celebrities, sports stars and film stars now talk in public about their experience of mental illness and mental distress may lead to a reduction in stigma.

O Against patients. The social and cultural contexts play a significant role in the development and understanding of stigma. In cultures where the locus of control of their illness is seen as external by patients (evil eye, bad deeds, etc.), the onus is likely to be taken away from the patient and stigma may be less. In societies where individuals are expected to look after themselves and their nuclear family, pressures to get better may well stigmatise patients and their illness.

O Against psychiatrists. Stigma and discrimination against psychiatrists, from a large number of sources, contribute to a sense of alienation from the medical profession as a whole. Stereotypes of psychiatrists being soft and of psychiatry as not being a science are common. These prejudices and discriminating behaviours have many consequences, including poor recruitment.

O Consequences. Stigma can cause delays in seeking help or complying with therapies. It has been shown that where doctors have better control of their own workload, rates of burnout are lower (Bhugra et al, 2008). Stigma against mental illness may translate into poor services and poor research funding as well. There is evidence that education may reduce stigma, which is a result of knowledge, attitudes and behaviour (see Evans-Lacko et al, 2010).

\section{Solutions}

These challenges can be managed using a number of strategies.

O Leadership. The first major step psychiatrists need to take is to become leaders in service planning, service delivery and evaluation of services. Medical training and an awareness of biopsychosocial models in making sense of aetiological factors make psychiatrists ideal leaders. Any leadership has to be in the cultural and social contexts. As leaders we should inspire, motivate, enable and empower others.

O Anti-stigma. There is no doubt that a lack of knowledge may contribute to negative attitudes, but increasing knowledge may not always change behaviour. However, concerted efforts in education will shift attitudes; such efforts should include not only working with local media but also personal contacts, particularly with patients and their carers.

O Quality improvement. In spite of limited resources, it is possible to focus on quality of services. This quality focus is not only on structures - physical environment - but also on processes, between patients and their psychiatrists. The task is to determine causes of problems and barriers in providing good services. But the quality has to be assessed in the context of local priorities and available resources. For psychiatrists, up-to-date knowledge and clinical skills remain critical in ascertaining and delivering quality.

o Prevention and health promotion. A considerable proportion of adult mental illness starts before people reach their mid-20s. Various risk factors (e.g. domestic violence, sexual or physical abuse, alcohol misuse) have been identified, especially in Black and minority ethnic individuals, gay, lesbian, transgender and bisexual individuals and in prisoners. A number of strategies can be used to reduce the development of psychiatric disorders. Similarly, early intervention in psychoses, addictions and dementia should enable a reduction in psychiatric and physical morbidity.

\section{Conclusions}

At the beginning of the second decade of the 21st century, new challenges are emerging which psychiatrists need to get to grips with. It is inevitable that some changes will occur at a faster speed than others. It is in the best interests of patients and society at large that psychiatrists and patients work together to deal with the challenges proffered by stigma, newer treatments and health promotion.

\section{References}

Bhugra, D. \& Gupta, S. (2010) Patient expectations from psychiatrists. In Professionalism in Mental Healthcare: Experts, Expertise and Expectations (ed. D. Bhugra \& A. Malik), pp. 92-100. Cambridge University Press.

Bhugra, D. \& Gupta, S. (2011) Globalisation: internal borders and external boundaries. In Migration and Mental Health (ed. D. Bhugra \& S. Gupta), pp. 56-67. Cambridge University Press.

Bhugra, D., Bhui, K. S. \& Ram Gupta, K. (2008) Burnout and stress among doctors and dentists in North India. International Journal of Culture and Mental Health, 1, 24-29.

Evans-Lacko, S., London, J., Little, K., et al (2010) Evaluation of a brief anti-stigma campaign in Cambridge: do short-term campaigns work? BMC Public Health, 10, 339.

Gupta, S. \& Bhugra, D. (2009) Globalization, economic factors and prevalence of psychiatric disorders. International Journal of Mental Health, 38, 53-65.

Mrazek, D. A. (2010) Psychiatric Pharmacogenomics. Oxford University Press. 